\title{
DESAIN SISTEM PEMBELAJARAN JARAK JAUH BERBASIS SMART CLASSROOM MENGGUNAKAN LAYANAN LIVE VIDEO WEBCASTING
}

\author{
Yasdinul Huda ${ }^{1)}$, Delsina Faiza ${ }^{2)}$ \\ ${ }^{1,2}$ Prodi Pendidikan Teknik Elektronika, Universitas Negeri Padang \\ e-mail : ${ }^{1}$ yasdinul5330@ft.unp.ac.id, ${ }^{2}$ delsina.faiza@,ft.unp.ac.id
}

\begin{abstract}
The research aims to provide broad access to education for people in the Industrial Revolution 4.0 through various higher education institutions that actively participate using the Blended Learning model. The longterm goal of this research is to develop innovative and flexible learning models based on Smart Classroom. System design in this study was developed to realize a balance between virtual teaching (virtual class) and face-to-face (physical class) that takes place at the same time using the Live Video Webcasting service. The research method uses a quantitative approach and the type of research is $R \& D$ adopting the Thiagarajan 4D development model. This research produces a Smart Classroom system based on Streaming Webcast through several stages, namely: (1) System Design, (2) System Creation, (3) System Testing. This developed system allows interaction in learning in the physical class as well as teaching in a virtual class remotely.Keywords: Revolusi Industri 4.0, Blended Learning, Smart Classroom, Live Video Webcasting.
\end{abstract}

Keywords : Industrial Revolution 4.0, Blended Learning, Smart Classroom, Live Video Webcasting

\section{INTISARI}

Penelitian bertujuan untuk memberikan akses pendidikan yang luas bagi masyarakat di era Revolusi Industri 4.0 melalui berbagai institusi pendidikan tinggi yang berpartisipasi aktif menggunakan model Blended Learning. Tujuan jangka panjang penelitian ini adalah untuk mengembangkan model pembelajaran inovatif yang fleksibel dan cerdas berbasis Smart Classroom. Desain sistem pada penelitian ini dikembangkan untuk mewujudkan keseimbangan antara pengajaran virtual (kelas maya) dan tatap muka (kelas fisik) yang berlangsung dalam waktu yang sama menggunakan layanan Live Video Webcasting. Metode penelitian menggunakan pendekatan kuantitatif dan jenis penelitian adalah R \& D mengadopsi model pengembangan 4D Thiagarajan. Penelitian ini menghasilkan sistem Smart Classroom berbasis Streaming Webcast melalui beberapa tahapan, yaitu: (1) Desain Sistem, (2) Pembuatan Sistem, (3) Pengujian Sistem. Sistem yang dikembangkan ini memungkinkan interaksi pembelajaran di kelas fisik sekaligus juga pengajaran di kelas virtual secara jarak jauh.

Kata Kunci : Revolusi Industri 4.0, Blended Learning, Smart Classroom, Live Video Webcasting

\section{PENDAHULUAN}

Isu berkaitan dengan pemerataan dan demokratisasi pendidikan, serta perluasan akses terhadap pendidikan berkualitas kepada seluruh lapisan masyarakat sudah lama menjadi perhatian pemerintah dan menjadi salah satu bidang unggulan dalam Renstra Penelitian Universitas Negeri Padang tahun 2016-2020 [1]. Penelitian ini dilakukan untuk mendukung pencapaian program pemerintah dan Renstra penelitian Universitas
Negeri Padang, khususnya pada topik Pengembangan Pembelajaran Berbasis IT terdapat dalam bidang unggulan Pendidikan Dan Ilmu Pendidikan.

Perluasan akses terhadap pendidikan berkualitas ini dianggap Pendidikan Jarak Jauh sebagai solusinya. Pendidikan Jarak Jauh (PJJ) atau yang lebih dikenal sebagai e-learning sudah menjadi bagian yang menyatu dalam dunia pendidikan di Indonesia, dan menjadi pilihan bagi 
masyarakat untuk memperoleh akses terhadap pendidikan. Situasi ini membuka kesempatan dan peluang bagi berbagai institusi pendidikan tinggi untuk berpartisipasi aktif dalam PJJ di abad 21 ini.

Menghadapi perkembangan zaman yang semakin pesat pada Abad 21, maka pembelajaran harus dirancang agar dapat mencapai kompetensi Abad 21. Salah satu dari enam unsur pembelajaran abad 21 [2] adalah literasi informasi dan literasi TIK. Agar kompetensiliterasi informasi dan literasi TIK mahasiswa juga berkembang maka integrasi TIK dalam pembelajaran perlu dilakukan. Pengintegrasian TIK termasuk internet sebagai alat pembelajaran dapat mendukung peningkatan kompetensi literasiinformasi dan literasi TIK mahasiswa secara efektif [3].

Dengan perkembangan teknologi TIK yang cepat, metode pembelajaran yang semakin fleksibel dan efisien memberi peluang dikembangkan dengan baik. Strategi pembelajaran atau pembelajaran yang disengaja dapat dikaitkan dengan menumbuhkan pengetahuan dan keterampilan bagi peserta didik. Dengan tujuan untuk mengembangkan kemampuan berbeda dari pelajar cerdas, kami menawarkan pedagogi cerdas dalam suatu kelas cerdas (Smart Classroom) dengan mengadopsi suatu metode praktis yang relevan, yaitu dengan mengkolaborasikan pembelajaran generatif(kelas maya) dan pengajaran berbasis kelas (kelas fisik), yang telah dikembangkan oleh [4].

Belajar adalah proses generatif. Dalam proses seperti itu, pelajar adalah penerima informasi aktif yang bekerja untuk membangun pemahaman yang berarti tentang informasi yang ditemukan di lingkungan [5]. Pembelajaran generatif dapat memungkinkan pembelajar untuk fleksibel menerapkan kecerdasan apa yang telah mereka pelajari dan hasilkan untuk berbagai situasi masa depan yang relevan [6].

Konsepdasar PengajaranGeneratif (MassBase Generatif Learning) melibatkan penciptaan dan penyempurnaan konstruksi mental pribadi tentang lingkungan[7]. Eagle [8] mengusulkan kerangka teoritisuntuk pembelajaran generatif yang menggabungkan konten dan analisis konteks. Tujuannya adalah untuk membiarkan siswa berpartisipasi dalam pembangunan konten yang ditransfer dan untuk membingkai pembelajaran dan mentransfer konteks untuk menciptakan interkonekstualitas. Ketika siswa belajar online, mereka dapat menghubungkan informasi baru ke informasi lama, memperoleh pengetahuan yang bermakna dan menggunakan kemampuan metakognitif mereka [9]. Kegiatan ini dapat mempromosikan siswa untuk berpartisipasi aktif dalam membangun konten yang relevan.

Pembelajaran online juga memungkinkan siswa untuk memangkas batasan waktu dan ruang [10]. Pembelajaran ini memiliki interaktivitas, kolaborasi, dan keaslian yang tinggi. Fitur-fitur ini dapat mendukung untuk membingkai waktu dan partisipasi untuk menciptakan intercontextuality. Kemudian dalam proses pembelajaran, mahasiswa memiliki kemampuan komunikasi dan kolaborasi.

Konsep dasar pengajaran dibedakan berbasis kelas (Class-Based Differentiated Instruction). Pembelajaran yang dibedakan adalah proses untuk mendekati pengajaran dan pembelajaran bagi siswa dengan kemampuan yang berbeda di kelas yang sama [11]. Ruang kelas dianggap sebagai komunitas bahwa siswa diperlakukan sebagai pembelajar individu [12]. Di bawah instruksi yang berbeda, semua peserta didik memiliki preferensi belajar yang disesuaikan dan belajar secara efektif.

Dalam penelitian ini Strategi pengajaran berbeda di rekayasa dalam 2 kondisi pembelajaran menggunakan model campuran (Blended Learning) yang menampilkan keseimbangan antara pengajaran virtual (kelas maya) dan tatap muka (kelas fisik) yang berlangsung dalam waktu yang sama, yang dikenal sebagai smart classroom berbasis live webcast. Proporsi setiap mode pengiriman akan bervariasi secara signifikan dan sangat terkait dengan peran dosen dalam memfasilitasi pembelajaran. eLearning tidak terbatas pada studi mandiri atau model pembelajaran jarak jauh, hal ini perlu menjadi pertimbangan penting untuk diterapkan di universitas negeri padang khususnya pada Jurusan Teknik Elektronika FT UNP.

Strategi pengajaran Smart Classroomspada Gambar 1 terdiri dari tiga komponen yang saling terkait dan saling bergantung:

1. Pedagogi Digital

2. Konten Digital (termasuk eCurriculum)

3. Ruang Belajar

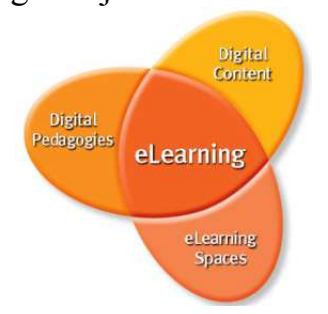

Gambar 1. Strategi Smart Classroom pada eLearning [13] 
Webcast [14] adalah presentasi media yang didistribusikan melalui Internet dengan menggunakan teknologi media streaming untuk mendistribusikan satu sumber konten pembelajaran ke banyak pendengar/pemirsa simultan melalui distribusi secara langsung atau sesuai permintaan.
Pada dasarnya, webcasting merupakan "Broadcasting" melalui Internet. Sistem Layanan Live video Webcasting ditampilkan pada Gambar 2.

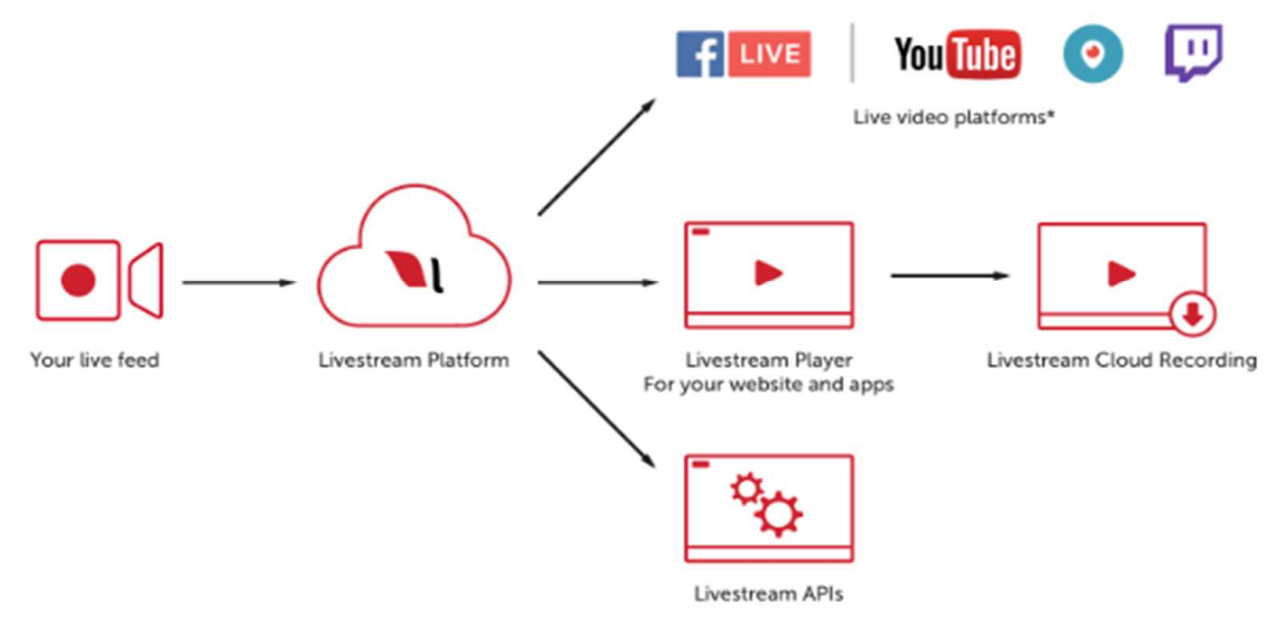

Gambar 2. Distribusi sumber konten ke banyak pendengar/pemirsa simultan pada Smart Classroom.

Manfaat live streaming pada pendidikan menurut [15] adalah:

1. Pengalaman Interaktif Langsung

Keuntungan terbesar dari live streaming adalah kemampuan siswa untuk memiliki pengalaman interaktif langsung. Misalnya, LiveEdu.tv menawarkan kesempatan kepada guru dan siswa untuk menjadi bagian dari komunitas yang lebih luas. Christopher Wolfram sedang menjelaskan kode di balik film, " Arrival ." Dia terus berinteraksi dengan penonton dan memberi mereka pengalaman interaktif tentang kode yang digunakan dalam film yang berjudul, "Arrival."

2. Pengalaman Belajar yang Lebih Baik

Belajar dari live stream adalah pengalaman yang sama sekali berbeda dibandingkan dengan kelas tradisional. Kelas tradisional tidak selalu merupakan lingkungan terbaik karena guru tidak dapat benar-benar fokus pada setiap siswa. Livestreams atau video yang direkam menawarkan kepada siswa kesempatan untuk meninjau kembali pelajaran sesuai keinginan mereka. Yang jelas, itu adalah keuntungan bagi siswa untuk memperkuat konsep. Penelitian Cisco tentang pembelajaran video juga memberikan pandangan yang sama seperti lebih dari $65 \%$ guru setuju bahwa hal itu membantu siswa.

3. Real-time dan On-demand Live Streaming Dengan perbaikan di hampir semua sektor, ada permintaan besar untuk topik baru yang perlu ditutupi. Streaming langsung memungkinkan institusi dan platform pendidikan menyediakan konten tepat waktu sesuai permintaan kepada pemirsa.Hal ini memungkinkan seseorang untuk mendapatkan akses ke materi pembelajaran mutakhir dan membantu mereka tumbuh.

4. Aksesibilitas

Aksesibilitas menjadi salah satu manfaat terbesar dari live streaming. Siapapun yang memiliki koneksi yang tepat dapat terhubung dan menjadi bagian dari masyarakat. Tidak ada aturan ketat yang harus dipatuhi saat menonton liveests. Area terpencil juga mendapat manfaat dari liveesting.

5. Belajar tentang Pemirsa

Pembelajaran online dan live streaming telah dimungkinkan karena kemajuan teknologi. Teknologi yang sama juga membantu pendidik memahami siswa dan pola belajar mereka. Pendidik juga bisa mempelajari kebiasaan belajar siswa. Dengan cara ini, 
mereka dapat membangun kursus dan memenuhi kebiasaan belajar setiap siswa. Anda bisa membaca "studi" oleh University of Maryland untuk mengetahui lebih banyak tentang pola yang bisa dipelajari tentang siswa.
Rhode Island School of Design [15] menyatakan bahwa Secara keseluruhan, Livestream adalah aset besar, karena kami menggunakannya untuk komunitas di luar kampus. Livestream mudah digunakan dan menawarkan layanan handal yang sesuai dengan kebutuhan kita dengan solusi fleksibel. Gambar 3 menampilkan Peralatan live streaming.

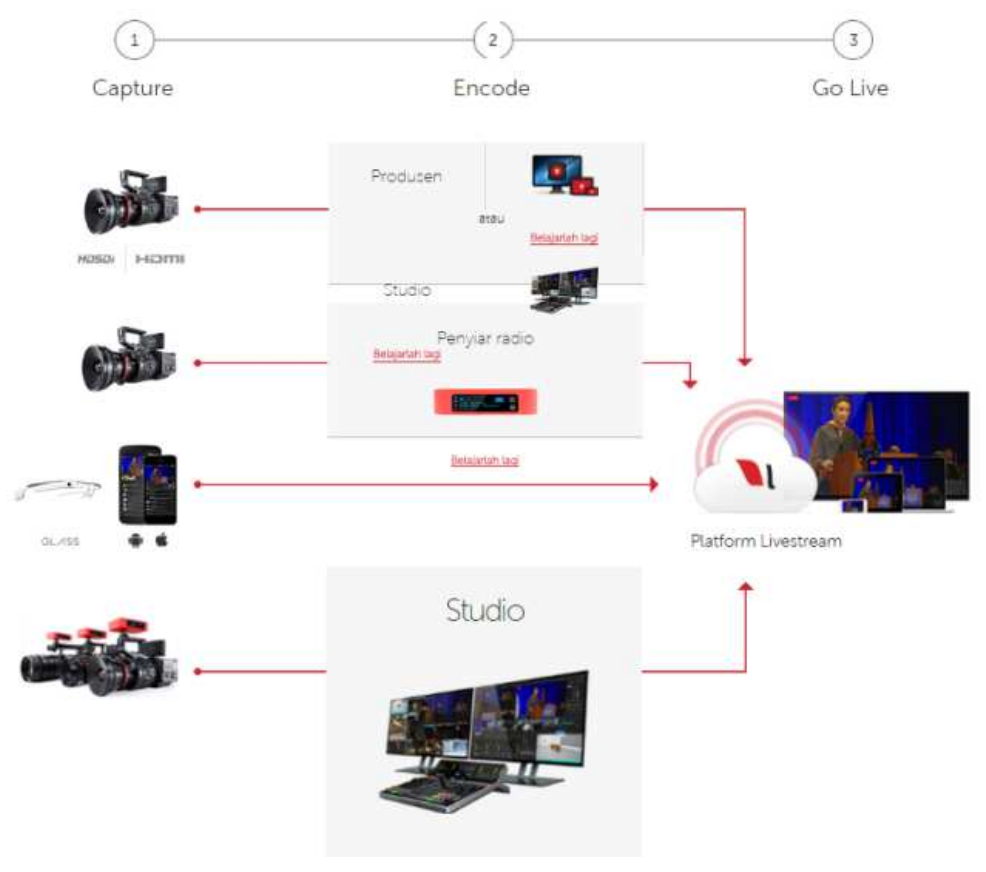

Gambar 3. Peralatan live video streaming (Dylan:2015)

Strategi pembelajaran yang diadopsi, memungkinkan terjadi interaksi pembelajaran dalam ruang kelas fisik atau dalam kelas maya dengan mengintegrasikan berbagai perangkat teknologi IT. Tujuan jangka panjang penelitian ini adalah untuk mengembangkan model pembelajaran inovatif yang fleksibel dan cerdas berbasis Smart Classroom dalam rangkamencapai kompetensi Abad 21. Smart Classroom mengintegrasikan pengenalan suara, visualisasi komputer, dan teknologi lain untuk memberikan pengalaman pendidikan jarak jauh (kelas maya) yang mirip dengan pengalaman kelas nyata.

\section{PENDEKATAN PEMECAHAN MASALAH}

Jenis Penelitian ini tergolong kedalam jenis penelitian eksperimen. Metode eksperimen adalah metode penelitian yang digunakan utuk mencari pengaruh perlakuan tertentu terhadap yang lain dalam kondisi yang terkendalikan [17]. Perlakuan adalah penggunaan live webcast sebagai media pembelajaran sebagai alat bantu penyampaian pesan.

Metode yang digunakan dalam pengembangan instrument/media adalah pendekatan penelitian pengembangan (Research and Development, R\&D).

1. Tahap analisis

Kegiatan analisis dilakukan melalui kegiatan studi lapangan dan studi literatur. Studi lapangan dilakukan dengan cara observasi langsung di jurusan Teknik Elektronika sebagai objek penelitian. Observasi yang dilakukan adalah dengan wawancara. Tujuan dari observasi untuk menentukan kebutuhan media yang sesuai dan mendukung live webcast pada desain Smart Classroom. Analisis berikutnya dengan kegiatan studi literatur dengan cara melakukan kajian teori melalui buku-buku, jurnal dan sumber informasi lainnya berkaitan dengan 
pengembangan Smart Classroom berbasis live webcastdi Jurusan Teknik Elektronika.

2. Tahap desain(design)

3. Tahap Pengembangan (Development)

a. Analisis kebutuhan

Pembuatan produk dilaksanakan setelah menganalisis kebutuhan dan pengumpulan komponen serta peralatan kerja. Analisis kebutuhan komponen dan alat kerja disesuaikan dengan hasil desain produk.

b. Pembuatan Smart Classroom berbasis live webcast sebagai media pengembangan Smart Classroom berbasis live webcast terbagi menjadi beberapa tahap, yaitu: (1) perancangan media, (2) pembuatan media, (3) pengujian media.

c. Ujicoba

Tahap ujicoba dilaksanakan untuk mendapatkan pernyataan kelayakan dari ahli media dan ahli materi. Ujicoba ini melibatkan dosen senior dan dosen untuk menilai produk sebelum diterapkan dalam pembelajaran. Hasil dari ujicoba dijadikan masukan untuk memperbaiki produk.

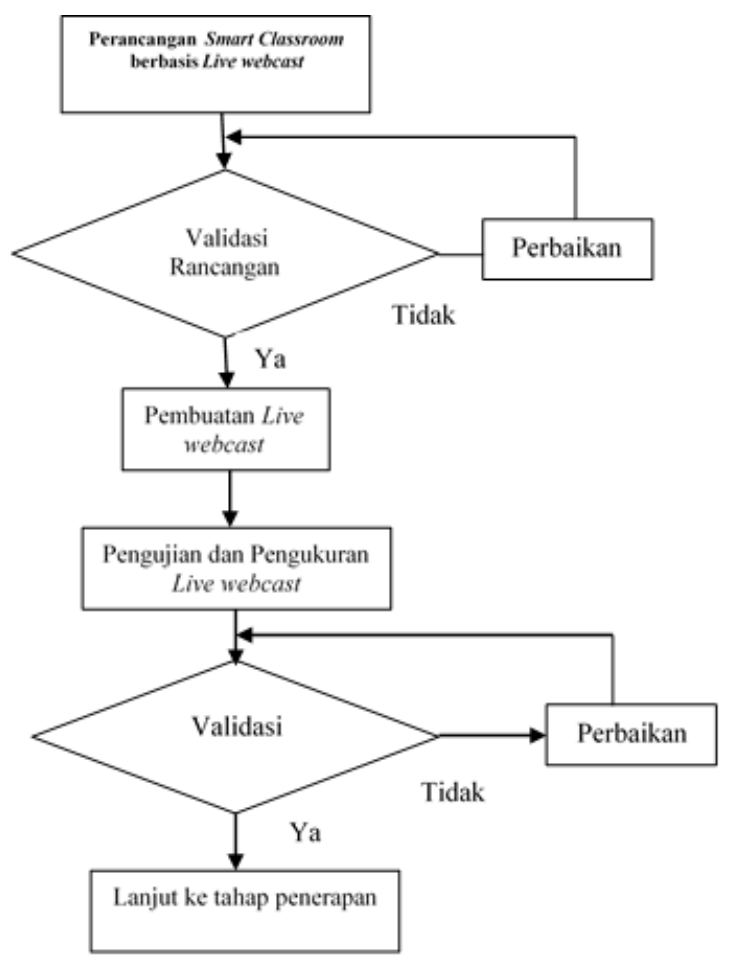

Gambar 4. Prosedur penelitian

\section{HASIL DAN PEMBAHASAN}

Strategi Pengajaran untuk menumbuhkan fleksibel dalam menerapkan kecerdasan terhadap apa yang telah peserta didik pelajari dan hasilkan untuk berbagai situasi masa depan yang relevan,kami menerapkan strategi instruksional seperti ditunjukkan pada Gambar 5. Strategistrategi ini termasuk instruksi berbasis-kelas, sebagai kelas fisik/virtual/jarak jauh dan Pembelajaran Generatif berbasis massa (melalui interaksi online secara dominan) sebagai kelas maya (live broadcast/webcast). Semua strategi ini mencakup pembelajaran formal dan informal, baik di dunia nyata maupun dunia digital.

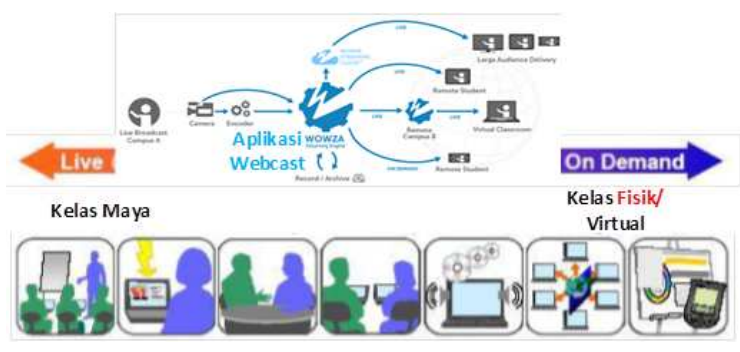

Gambar 5. Strategi pembelajaran generatif learning (live broadcast) dan berbasis kelas (live vitual) [17].

a. Kelas Maya

Kelas maya menerapkan metode Pembelajaran Generatif seperti digambarkan pada Gambar 6 (a). Pembelajaran Real Time terjadwal secara kolektif atau kolaborative menggunakan peralatan TIK (Sistem Webcast, konsep penyiaran melalui Web), adanya simulasi maya (peserta didik, fasilitator atau instruktur) sebagai sumber Video Conference melalaui Internet (IP Model).

Aplikasi Webcasting (Zoom/ Wirecast/ Wowza) menyiarkan dari satu sumber ke beberapa penerima pasif, baik langsung atau permintaan (on Demand). Infrastruktur kelas ini di rancang di lab. Teknik Elektronika lantai 3 gedung ITL FT UNP, sebagaimana ditampilkan pada Gambar 6 (a).

b. Kelas Virtual

Kelas virtual menerapkan Pengajaran berbasis kelas seperti digambarkan pada Gambar 6 (b). Pembelajaran secara independen (ruang dan waktu). Peserta didik dapat berinteraksi dengan materi kursus dan satu sama lain pada waktu yang mereka pilih dan atau waktu ditetapkan dan atau Menggunakan teknologi TIK melalui IP Model [Aplikasi Webcast (Zoom/Wirecast/Wowza)] sebagai penerima pasif, baik langsung (Live) atau 
permintaan (on Demand). Dalam design yang di uji coba adalah pada aplikasi Zoom.

Peserta didik bisa hadir secara fisik/virtual untuk terlibat dalam belajar dengan peserta didik lain melalui forum diskusi pada
Aplikasi Webcast. Infrastruktur kelas ini di rancang di lab. E59 blok Jurusan Teknik Elektronika, sebagaimana ditampilkan pada Gambar 6 (b).
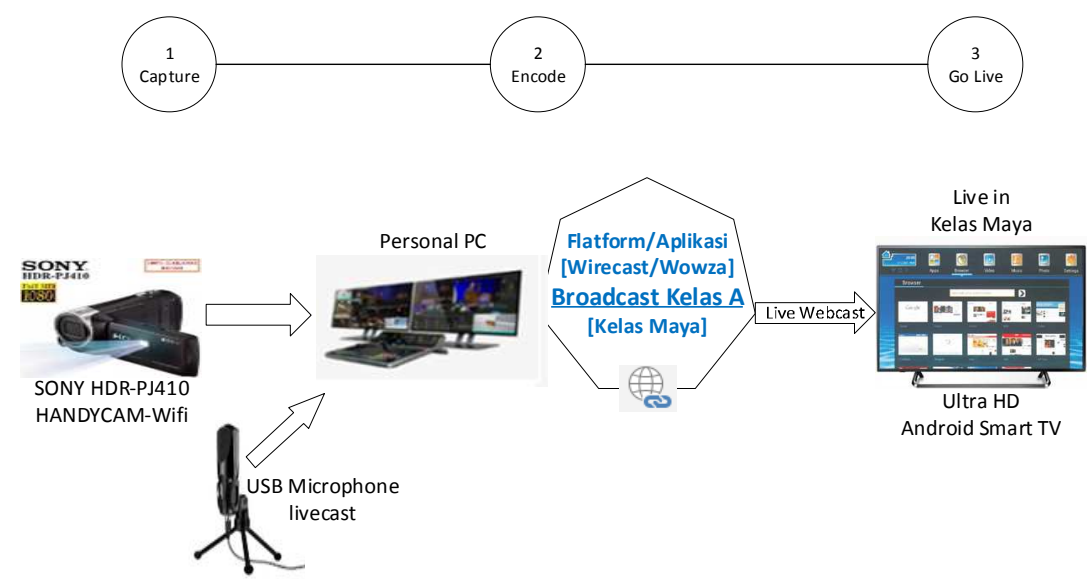

Gambar 6 (a). Design Instalasi Peralatan Layanan Live Video Webcasting di Kelas Maya

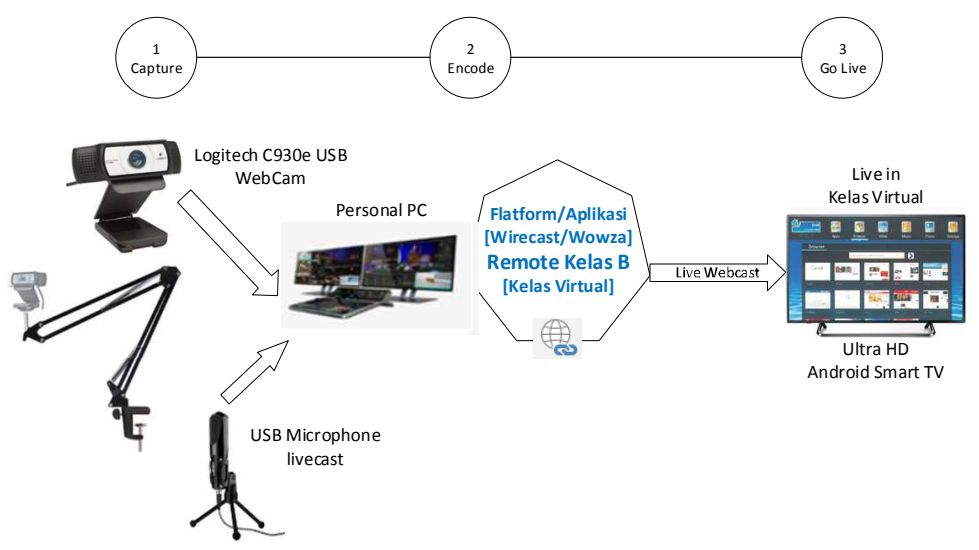

Gambar 6 (b). Instalasi Peralatan Layanan Live Video Webcasting di Kelas Virtual

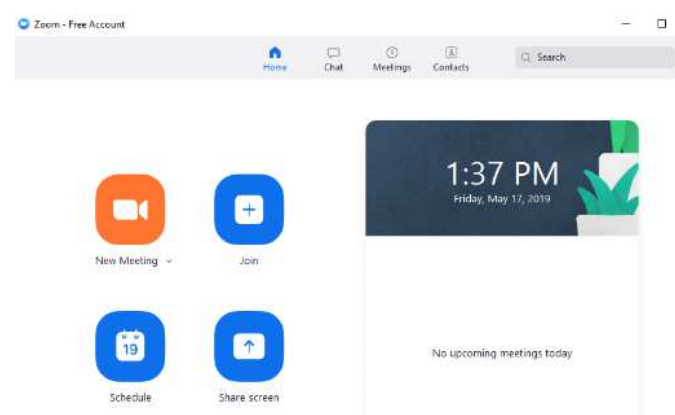

(a). Halaman Webcasting Zoom Meeting

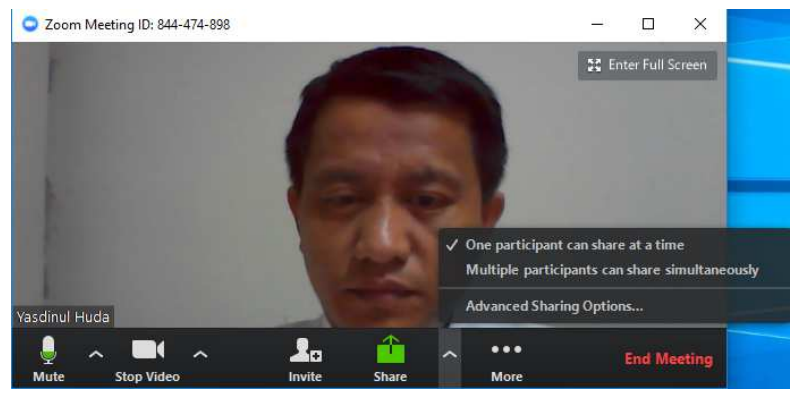

(b). Halaman Awal Sumber Informasi (guru) dalam mode satu peserta.

Gambar 7 Salah satu contoh Webcasting Zoom untuk Layanan Live Video Webcasting 
Melalui konferensi video dan teknologi audio visual lainnya menggunakan webcast, memungkinkan pendidik menjangkau lebih banyak siswa dan memberi mereka pengalaman pendidikan yang lebih interaktif, baik di kelas yang sama atau di kota yang berbeda melalui suatu layanan live webcast. Livestream adalah aset besar, karena dapat digunakan untuk komunitas pembelajaran di luar kampus, ini memungkinkan terhubung dengan peserta didik di kelas dan peserta didik lain yang tidak dapat menghadiri kelas. Livestream mudah digunakan dan menawarkan layanan handal yang sesuai dengan kebutuhan Universitas Negeri Padang dengan solusi fleksibel.

Strategi pembelajaran atau pembelajaran yang rekayasa ini akan menumbuhkan pengetahuan dan keterampilan bagi peserta didik. Dengan tujuan untuk mengembangkan kemampuan berbeda dari pelajar cerdas melalui pedagogi cerdas yang ditawarkan dalam suatu kelas cerdas (Smart Classroom) dengan mengadopsi suatu metode praktis yang relevan, yaitu dengan mengkolaborasikan pembelajaran generatif (kelas maya) dan pengajaran berbasis kelas (kelas fisik), yang dapat dikembangkan.

\section{KESIMPULAN}

Penggunaan webcast sebagai media live broadcast pembelajaran, memungkinkan pendidik menjangkau lebih banyak siswa dan memberi mereka pengalaman pendidikan yang lebih interaktif, baik di kelas yang sama atau di kota (di kelas) yang berbeda melalui suatu layanan live webcast.

Strategi pembelajaran untuk mengembangkan kemampuan berbeda dari pelajar cerdas melalui pedagogi cerdas yang ditawarkan dalam suatu kelas cerdas (Smart Classroom) dengan mengadopsi suatu metode praktis yang relevan, yaitu dengan mengkolaborasikan pembelajaran generatif (kelas maya) dan pengajaran berbasis kelas (kelas fisik), yang dapat dikembangkan.

\section{DAFTAR PUSTAKA}

[1] LP3M. Renstra Penelitian Universitas Negeri Padang tahun 2016-2020. Buku panduang penelitian UNP. 2018.

[2] Partnership for 21st centuryskills. Learning for the 21st Century: A Report and MILE Guide for 21 st Century Skills. 2002.
[3] Yilmaz, M. B., \& Orhan, F. High School Students Educational Usage of Internet and Their Learning Approaches. World Journal on Education Tecnology, vol 2 no 2, pp. 100-112. 2010.

[4] Zhi-Ting Zhu. A research framework of smart education. Explore Journal. SpringerOpen. 2016.

[5] M.C. Wittrock, A generative model of mathematics education. J. Res. Math. Educ. Vol 5 no 4, pp. 181-196. 1974.

[6] R.A. Engle. Framing interactions to foster generative learning: a situative explanation of transfer in a community of learners classroom. J. Learn. Sci. Vol 15 no 4, pp. 451-498. 2006.

[7] D. Ritchie, C. Volkl, Effectiveness of two generative learning strategies in the science classroom. Sch. Sci. Math. vol 100 no 2, pp. 83-89 2000.

[8] R.A. Engle, Framing interactions to foster generative learning: a situative explanation of transfer in a community of learners classroom. J. Learn. Sci. Vol 15 no 4, pp. 451-498. 2006.

[9] Bonk, C. J., \& Reynolds, T. H. Learnercentered web instruction for higher-order thinking, teamwork, and apprenticeship. In B. H. Khan (Ed.), Web-based instruction pp. 167-178. Englewood Cliffs, NJ: Educational Technology Publications. 1997.

[10] R.A. Cole. Issues in Web-based pedagogy: A critical primer. Greenwood Press, Westport. 2000.

[11] T. Hall. Differentiated instruction. National Center on, Wakefield. 2002.

[12] D. Lawrence-Brown. Differentiated instruction: Inclusive strategies for standardsbased learning that benefit the whole class. American secondary education, pp. 34-62. 2004.

[13] Scybite. eLearning for smart classrooms Education Queensland. 2008.

[14] Shiao, Dennis (26 December 2012). "Webcasting 101: Planning and Executing High Quality Webcasts". INXPO. Retrieved 15 May 2013. 
[15] Emergingedtech. Educational benefits and opportunities of live streaming. 2017. Website. http://www.emergingedtech.com/2017/04/edu cational-benefits-and-opportunities-of-livestreaming/. diakses tanggal 30 Januari 2018.

[16] Rhode Island School of Design (Dylan Costa 2015)

[17] Y. Huda, K. Rukun, dkk. Live Webcast System Design For Smart Classroom Learning In Electronic Engineering Department. International Conference : IT-Profesional and Vocational Education in Information Technology (IVET) on KONASPI 2019. GS.AB.437 pp.107. 2019. 